\title{
Retraction Note: Spatial distribution of heavy metals in groundwater based on structural equation and development of leisure agriculture tourism
}

\section{Shen Yao ${ }^{1}$}

Published online: 17 November 2021

๑) Saudi Society for Geosciences 2021

\section{Correction to: Arabian Journal of Geosciences (2021) 14: 1708}

https://doi.org/10.1007/s12517-021-08005-2

The Editor-in-Chief and the Publisher have retracted this article because the content of this article is nonsensical. The peer review process was not carried out in accordance with the Publisher's peer review policy. The author has not responded to correspondence regarding this retraction.

The original article can be found online at https://doi.org/10.1007/ s12517-021-08005-2.

\section{Shen Yao}

shenyaonc@126.com

1 Land Resources and Environmental College, Jiangxi

Agricultural University, Nanchang, China 